\title{
The Role of Ultrasound in Psoriatic Arthritis - Do We Need a Score?
}
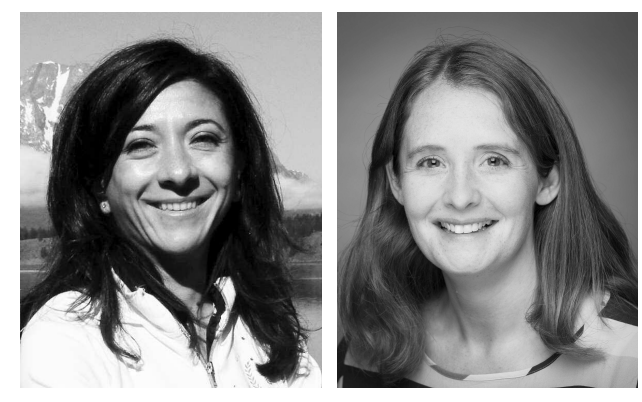

Enthesitis is one of the hallmarks of the spondyloarthritis $(\mathrm{SpA})$ group, including psoriatic arthritis (PsA $)^{1,2}$. Enthesitis is usually defined as inflammation at the site of attachment of a tendon, ligament, and capsule onto bone, which can cause significant pain and disability for patients ${ }^{2}$. In recent years, the interest in this domain of disease has grown with increasing evidence of its prevalence and potential importance in the pathogenesis of the disease ${ }^{3}$. One of the limitations in understanding the exact role of enthesitis in these diseases has been the difficulty in assessing this feature ${ }^{3,4}$. Usually enthesitis is evaluated by clinical assessment, which measured the pain provoked by physical examination of entheseal sites. However, tenderness at the entheseal site does not always denote inflammation, and its absence does not rule out enthesitis. The introduction of new drugs and the wider use of imaging, especially magnetic resonance imaging and ultrasound (US) in clinical and research practice, highlight the pivotal role of enthesitis for the diagnosis and management of both SpA (axial and peripheral) and PsA. Nevertheless, it has frequently been shown that clinical assessment of pain at tendon insertions does not always correlate with imaging assessment of inflammation $5,6,7,8$. The clinical examination of enthesitis may also identify pain from tendinosis, from nearby joint synovitis, or from other pain mechanisms without any true involvement of the adjacent enthesis.

In addition, it has been reported that a significant proportion of patients with PsA, and indeed patients with psoriasis, have subclinical enthesitis with inflammation seen on imaging, without tenderness at the insertion ${ }^{9}$.

US has been proven to be a valuable tool to assess entheseal involvement across the SpA spectrum, including $\mathrm{PsA}^{7,8,9}$. Extensive descriptions of the US findings defining enthesitis as well as the application of the technique as a management tool of both SpA and PsA have been published several times since the first observation by Lehtinen, et al in $1995^{6,7,8,10,11,12}$

In routine clinical practice, there has been an increase in the use of US for both diagnosis and monitoring of PsA. In borderline cases with psoriasis and musculoskeletal (MSK) pain, US can be very helpful to differentiate inflammatory synovitis or enthesitis from other common conditions including osteoarthritis (OA) and mechanical joint pain ${ }^{13,14,15}$. Once a diagnosis is established, US can also be used to quantify inflammation in joints and tendons if there is doubt in the clinical examination ${ }^{13}$.

The US appearance of enthesitis can be defined as a combination of morphological changes in greyscale and inflammatory findings in Doppler mode ${ }^{7,8,9,16}$. The Outcome Measures in Rheumatology (OMERACT) US group has established a definition of enthesitis and the different elementary inflammatory and structural components that can be visualized (hypoechogenicity, thickening, bone erosion, enthesophytes, calcification, Doppler signal) at entheses, as well as their scoring ${ }^{17,18}$. The development and validation process were performed on both $\mathrm{SpA}$ and PsA, allowing a standardization of this tool for research. Since the first OMERACT publication in $2004{ }^{19}$ proposing a preliminary definition of enthesopathy, and the more recent publication on which elementary features compose the enthesitis, an improvement in the quality of the published studies has been observed. Therefore, at the entheseal level, there is no need to develop new US scoring methods for detecting the presence of enthesitis.

The unmet questions at the moment are the following: Which and how many entheseal sites should be scanned for developing a scoring system at patient level? Should these entheseal sites be different according to the purpose of the US examination (i.e., diagnostic purpose or monitoring purpose)? And finally, should the entheseal sites examined in PsA differ from those examined in SpA?

In their study described in this issue of The Journal, Tom and colleagues tried to develop an entheseal scoring system at patient level that could identify which enthesis should be evaluated by US for detecting PsA ${ }^{20}$. They scanned a pre-defined set of entheses in 50 consecutive patients with

See Sonographic enthesitis score, page 384

Personal non-commercial use only. The Journal of Rheumatology Copyright (c) 2019. All rights reserved. 
active PsA to investigate US evidence of enthesitis. These patients were compared to 50 healthy controls who were similar in age and sex but did have a lower body mass index than the patients with PsA. In keeping with previous data, a significant proportion of patients $(42 \%)$ had a clinically tender entheseal insertion, although this was also seen in $22 \%$ of controls. In the study, 11 different entheseal sites were scanned bilaterally ${ }^{20}$. The most frequent abnormalities, at entheseal level, found in PsA were enthesophytes, thickening, and hypoechogenicity, but these were also reasonably frequent in controls. In contrast, Doppler changes, bony proliferation, and erosions were less common (5-12\% of PsA cases), but appeared to be more specific for PsA. When considering individual sites of enthesitis, key sites that differentiated PsA from controls were patellar ligament insertions, Achilles, plantar fascia insertion, common extensor tendon insertion at lateral epicondyle of the elbow, and supraspinatus insertion. These sites are similar to previously published reports $^{8}$, with the addition of the greater trochanter insertion, which was not assessed in this study ${ }^{8}$.

Although the study provides further evidence of the high prevalence of entheseal changes in patients with PsA, and the high prevalence of asymptomatic findings (because the entheseal involvement was detected more frequently with US than with clinical assessment based on tenderness), it does not, however, answer completely the question of which sites are more specific for the presence of PsA and which should be scanned in priority ${ }^{21}$.

The results of this study highlight once again what has been recently published ${ }^{21,22}$ : the discrepancy between clinical and US findings and the absence of correlation between clinical characteristics of active enthesitis and US inflammatory activity 6,22 .

The lack of correlation between clinical and US evaluation of enthesitis, as well as the different US definitions of enthesitis used to date, have generated discordant data about the capability of the technique to clearly differentiate between enthesis involvement in SpA or PsA and in other pathologies. A common US definition of enthesitis for the SpA group is therefore highly sought. This definition has been developed by the OMERACT US group ${ }^{17}$.

The OMERACT definition points out the importance of Doppler signal to distinguish between enthesitis in SpA or PsA and other pathologies or normal subjects. Although greyscale components are important for detecting the presence of structural changes, they are alone unable to differentiate between mechanical and inflammatory involvement $^{7,23}$. The lack of discriminant capability of greyscale findings has been already reported ${ }^{6,23}$.

The results of this study ${ }^{20}$, along with those from the previous cited studies, lead to the question of whether inflammatory findings should be weighted more heavily than structural damage in the development of an US enthesitis score, at patient level, to differentiate better PsA-related enthesitis from other biomechanical factors potentially affecting the entheses.

In the Tom, et al study ${ }^{20}$, patients were compared to healthy controls, which does not mirror the potential use of US in diagnosis ${ }^{21}$. In this context it would be useful to follow on from this with a comparison of patients with psoriasis and other MSK complaints (e.g., OA, mechanical joint pain). This may help us understand the key differentiators to aid diagnosis of PsA within patients with psoriasis and MSK symptoms. Additional longitudinal data on patients with psoriasis who may develop PsA may also help us to understand more about the primary pathology of PsA and the spectrum of disease, and the role of the identified US lesions at different entheseal sites.

It is well recognized that clinical assessment of enthesitis has limitations and that imaging may have a key role to play in assessing this domain of PsA. Therefore, much effort should be put into keeping the field unified. There are 2 potential roles for imaging in this sphere: first, the opportunity to validate US as an outcome measure of enthesitis in PsA to be used in clinical practice. US definition of enthesitis and of the elementary lesions has been agreed on and published by the OMERACT US group. An extensive scanning protocol is currently being performed in a number of clinical trials. This will allow analysis of which features are sensitive to change in longitudinal studies and which sites of the body should be included in an optimal disease activity score.

Second, there is the potential to improve the use of US in diagnosis and classification of patients with PsA among those with psoriasis. Therefore, this study can be considered a first attempt to develop a US scoring system at the patient level that can identify which entheses should be scanned in patients with PsA and which lesions should be more weighted ${ }^{20}$. However, a big effort is required to identify specific inflammatory and structural changes that discriminate between disease and mechanical involvement.

Members of the GRAPPA US group have significant experience in longitudinal inception psoriasis cohorts, the OMERACT US group has developed a validated scoring, and there may be potential to include US in these studies, to support the differentiation of PsA from other MSK symptoms in patients with psoriasis.

\footnotetext{
MARIA ANTONIETTA D'AGOSTINO D, MD, PhD, Rheumatology Department, AP-HP, Hôpital Ambroise Paré, INSERM U1173, Labex Inflamex, Université Versailles St-Quentin en Yvelines, Boulogne-Billancourt, France;

LAURA C. COATES ${ }^{D}$, $M B C h B, P h D$,

Nuffield Department of Orthopaedics,

Rheumatology and Musculoskeletal Sciences,

University of Oxford,

Oxford, UK.
} 
Address correspondence to L.C. Coates, Nuffield Department of Orthopaedics, Rheumatology and Musculoskeletal Sciences, Botnar Research Centre, Windmill Road, Oxford OX3 7LD, UK. E-mail: laura.coates@ndorms.ox.ac.uk. L.C. Coates is a UK National Institute for Health Research (NIHR) Clinician Scientist and Senior Clinical Research Fellow funded by an NIHR Clinician Scientist award. The research was supported by the NIHR Oxford Biomedical Research Centre. The views expressed are those of the author(s) and not necessarily those of the UK National Health Service, the NIHR, or the UK Department of Health.

\section{REFERENCES}

1. Ball J. Enthesopathy of rheumatoid and ankylosing spondylitis. Ann Rheum Dis 1971;30:213-23.

2. Benjamin M, McGonagle D. The anatomical basis for disease localization in seronegative spondyloarthropathy at entheses and related sites. J Anat 2001;199:503-26.

3. Schett G, Lories RJ, D'Agostino MA, Elewaut D, Kirkham B, Soriano ER, et al. Enthesitis: from pathophysiology to treatment. Nat Rev Rheumatol 2017;21:731-41.

4. Polachek A, Li S, Chandran V, Gladman DD. Clinical enthesitis in a prospective longitudinal psoriatic arthritis cohort: incidence, prevalence, characteristics and outcome. Arthritis Care Res 2016;69:1685-91.

5. Lehtinen A, Taavitsainen M, Leirisalo-Repo M. Sonographic analysis of enthesopathy in the lower extremities of patients with spondylarthropathy. Clin Exp Rheumatol 1994;12:143-8.

6. Lehtinen A, Leirisalo-Repo M, Taavitsainen M. Persistence of enthesopathic changes in patients with spondylarthropathy during a 6-month follow-up. Clin Exp Rheumatol 1995;13:733-6.

7. Balint PV, Kane D, Wilson H, McInnes IB, Sturrock RD Ultrasonography of entheseal insertions in the lower limb in spondyloarthropathy. Ann Rheum Dis 2002;61:905-10.

8. D'Agostino MA, Said-Nahal R, Hacquard-Bouder C, Brasseur JL, Dougados M, Breban M. Assessment of peripheral enthesitis in the spondylarthropathies by ultrasonography combined with power Doppler: a cross-sectional study. Arthritis Rheum 2003;48:523-33.

9. Naredo E, Möller I, de Miguel E, Batlle-Gualda E, Acebes C, Brito $\mathrm{E}$, et al. High prevalence of ultrasonographic synovitis and enthesopathy in patients with psoriasis without psoriatic arthritis: a prospective case-control study. Rheumatology 2011 Oct; 50:1838-48.

10. D'Agostino MA, Aegerter P, Bechara K, Salliot C, Judet O, Chimenti MS, et al. How to diagnose spondyloarthritis early? Accuracy of peripheral enthesitis detection by power Doppler ultrasonography. Ann Rheum Dis 2011;70:1433-40.

11. de Miguel E, Cobo T, Muñoz-Fernández S, Naredo E, Uson J, Acebes JC, et al. Validity of enthesis ultrasound assessment in spondyloarthropathy. Ann Rheum Dis 2009;68:169-74.

12. Gandjbakhch F, Terslev L, Joshua F, Wakefield RJ, Naredo E, D'Agostino MA, et al. Ultrasound in the evaluation of enthesitis: status and perspectives. Arthritis Res Ther 2011;13:R188.
13. Marchesoni A, De Lucia O, Rotunno L, De Marco G, Manara M. Entheseal power Doppler ultrasonography: a comparison of psoriatic arthritis and fibromyalgia. J Rheumatol Suppl. 2012 Jul;89:29-31.

14. Marchesoni A, De Marco G, Merashli M, McKenna F, Tinazzi I, Marzo-Ortega $\mathrm{H}$, et al. The problem in differentiation between psoriatic-related polyenthesitis and fibromyalgia. Rheumatology 2018;57:32-40.

15. van der Ven M, Karreman MC, Weel AE, Tchetverikov I, Vis M, Nijsten TE, et al. Adding ultrasound to clinical examination reduced frequency of enthesitis in primary care psoriasis patients with musculoskeletal complaints. Clin Exp Rheumatol 2016;34:1020-5.

16. Aydin SZ, Bas E, Basci O, Filippucci E, Wakefield RJ, Celikel C, et al. Validation of ultrasound imaging for Achilles entheseal fibrocartilage in bovines and description of changes in humans with spondyloarthritis. Ann Rheum Dis 2010;69:2165-8.

17. Balint PV, Terslev L, Aegerter P, Bruyn GAW, Chary-Valckenaere I, Gandjbakhch F, et al. Reliability of a consensus-based ultrasound definition and scoring for enthesitis in spondyloarthritis and psoriatic arthritis: an OMERACT US initiative. Ann Rheum Dis 2018 Aug 3 (E-pub ahead of print).

18. Terslev L, Naredo E, Iagnocco A, Balint PV, Wakefield RJ, Aegerter $\mathrm{P}$, et al. Defining enthesitis in spondyloarthritis by ultrasound: results of a Delphi process and of a reliability reading exercise. Arthritis Care Res 2014;66:741-8.

19. Wakefield R, Balint PV, Szkudlarek M, Filippucci E, Backhaus M, D'Agostino MA, et al. Musculoskeletal ultrasound including definitions for ultrasonographic pathology. J Rheumatol 2005;32:2485-7.

20. Tom S, Zhong Y, Cook R, Aydin SZ, Kaeley G, Eder L. Development of a preliminary ultrasonographic enthesitis score in psoriatic arthritis - GRAPPA Ultrasound Working Group. J Rheumatol 2018;45:384-90.

21. Wervers K, Vis M, Rasappu N, van der Ven M, Tchetverikov I, Kok MR, et al. Modification of a sonographic enthesitis score to differentiate between psoriatic arthritis and young healthy volunteers. Scand J Rheumatol 2018;47:291-4

22. Michelsen B, Diamantopoulos AP, Soldal DM, Hammer HB, Kavanaugh A, Haugeberg G. Achilles enthesitis defined by ultrasound is not associated with clinical enthesitis in patients with psoriatic arthritis. RMD Open 2017;3:e000486.

23. Feydy A, Lavie-Brion MC, Gossec L, Lavie F, Guerini H, Nguyen C, et al. Comparative study of MRI and power Doppler ultrasonography of the heel in patients with spondyloarthritis with and without heel pain and in controls. Ann Rheum Dis 2012; 71:498-503

J Rheumatol 2019;46:337-9; doi:10.3899/jrheum.181044 